\title{
Editorial Aspect of the Methodology of the Dissertations at The Faculty of Medicine of Setif
}

\author{
Djamila. Adjiri \\ Physiology laboratory. Faculty of Medicine - Ferhat ABBAS University - Sétif 1 - ALGERIA \\ DOI: 10.29322/IJSRP.11.12.2021.p12011 \\ http://dx.doi.org/10.29322/IJSRP.11.12.2021.p12011
}

\section{Abstract- Introduction- objectives:}

Being an original work, the writing and the elaboration of a thesis must resemble a research work, and must meet the fundamental requirement of an appropriate methodology given that it must constitute the culmination of in-depth and rigorous personal work. The precision of the description of the methods is fundamental and allows the possibility of reproduction of the work of the authors.

The aim of this work was to make a contribution to improving the quality of the scientific medical writing of the end of studies theses at the Faculty of Medicine of Sétif through an evaluation study, and an action of introduction to techniques and rules in this area, as well as an evaluation of its impact.

\section{Material and methods:}

This is a comparative survey of the "before - after" type focusing on the study of the quality of scientific medical writing of the "methods" chapter of 109 end-of-study dissertations carried out at the level of the two medical departments. dental and pharmacy from the Faculty of Medicine of Sétif before and after a training session in the field and this during the academic years 2014 - 2015, for the first stage prior to training; and 2015 - 2016, for the second stage, after the training.

\section{Results:}

Apart from the sample size and the statistical techniques used, the parameters relating to the methodological aspect were specified for three quarters to two thirds of the memories studied, and with significantly higher frequencies at the level of the pharmacy department giving odds- ratios varying between 7 and 14 (p<1 p. 1000).

\section{Discussion - Conclusion:}

In addition to the clear predominance of clinical cases at the level of the dental department, the great diversity of the types of studies carried out was at the origin of that of the observed results. Despite a relatively satisfactory level of the editorial aspect of the methodology of the dissertations studied, the integration of training programs in the subject in the two cycles, graduate and post-graduate, is a necessity. It would constitute a means of learning, useful for the whole career of the students; and a means of development for professionals and teachers. It would certainly contribute to improving the quality of scientific texts, final theses, doctoral theses, communications and publications, and therefore to the promotion of scientific production.
Index Terms- Dissertation - Methodology - Medical writing Setif.

\section{INTRODUCTION}

$\mathrm{I}$ $\mathrm{n}$ order to promote the articulation between the achievements of training and professional experience, many training paths include in their program the completion of a thesis or a dissertation which is essential for obtaining the diploma. The dissertation is original work with the aim not to copy randomly compiled information from the literature, but to learn methods of reasoning in clinical medicine and simple methods of writing well. Learning which will be useful throughout the career [1-3]. It must make it possible to apply the scientific and clinical approaches learned during the studies. It is a school of methodology, writing and learning of literature analysis. Their writing and development must be like research work and must meet the fundamental requirement of an appropriate methodology since it must be the result of in-depth and rigorous personal work [1].

The appearance of the dissertations often remains mediocre, without real significance, akin to a work, sometimes very short, bringing together poorly exploited observations, presenting a compilation of works of little interest, and presented without real critical thinking; and, on the one hand, remains undeniably linked to an information deficit and a lack of methodological reflection and training in the practice of scientific writing $[1,4]$. On the other hand, the evaluation of manuscripts always remains focused much more on the content to ensure the accuracy, importance and originality of the published texts and their interest for the reader [5], while the editorial aspect and form are more or less ignored when the corresponding rules and techniques are not ignored. In the "Methods" chapter, precision should guide the inclusion and exclusion criteria of the study material; the description of what we sought to assess; and the criteria on which the results were judged, leaving no room for vagueness. The precision of the description of the methods allows the possibility of reproduction of the work of the authors [6]. Since the reintroduction of the realization of a dissertation or an exercise thesis in the cycle of graduation studies with a view to obtaining the diploma of Doctor of Pharmacy and Doctor of Dentistry [7, 8], what about the quality of the scientific writing of this type of production at the local level?

The objective of our work was to contribute to improving the quality of the scientific medical writing of the dissertations at the Faculty of Medicine of Sétif through an evaluation study, an initiation action. techniques and rules in this area, as well as an 
assessment of its impact; and finally, a contribution to the establishment of objective criteria for the evaluation of the editorial quality of manuscripts.

\section{OBJECTIVE:}

- Contribute to improving the quality of the scientific medical writing of the dissertations at the Faculty of Medicine of Sétif, in particular in their section reserved for the chapter of methods.

\section{METHODS:}

- Type of study:

This is a comparative study of the "before - after" type [9] relating to the study of the quality of scientific medical writing of the "methods" chapter of the dissertations. before and after a training session in the field.

- Study population:

The study population is represented by all the dissertations produced at the two departments of dentistry and pharmacy of the Faculty of Medicine of Sétif, during the university years 2014 2015 , for the first step prior to training; and 2015 - 2016, for the second stage, after the training. The study size was 109 research dissertations, 11 compilation dissertations, were dropped from the review.

- Study variables:

The study of the various variables focused only on the quality and compliance with the rules of scientific medical writing. The study of the scientific content of theses was not addressed.

The variables studied are:

- Identification data: The academic year, the production department, the rank of the supervisor, the number of authors and the type of thesis.

Table 1: Distribution of the dissertations according to the constituent elements the methodology and study protocol.

\begin{tabular}{lllc}
\hline \multirow{2}{*}{ Constituent elements } & \multicolumn{1}{l}{ Yes } & No & Total \\
\cline { 2 - 4 } & Workforce (\%) & Workforce (\%) & Workforce (\%) \\
\hline Study type & $81(74,3)$ & $28(25,7)$ & $\mathbf{1 0 9}(\mathbf{1 0 0 , 0})$ \\
Study population / Target & $84(77,1)$ & $25(22,9)$ & $\mathbf{1 0 9}(\mathbf{1 0 0 , 0})$ \\
Sample size & $15(17,8)$ & $94(86,2)$ & $\mathbf{1 0 9}(\mathbf{1 0 0 , 0})$ \\
Variables studied & $87(79,8)$ & $22(20,2)$ & $\mathbf{1 0 9}(\mathbf{1 0 0 , 0})$ \\
Judgment criteria & $70(64,2)$ & $39(35,8)$ & $\mathbf{1 0 9}(\mathbf{1 0 0 , 0})$ \\
Techniques used & $76(69,7)$ & $33(30,3)$ & $\mathbf{1 0 9}(\mathbf{1 0 0 , 0})$ \\
Statistical tests used & $25(22,9)$ & $84(77,1)$ & $\mathbf{1 0 9}(\mathbf{1 0 0 , 0})$ \\
\hline
\end{tabular}

Table 2: Comparative study of the methodology and the study protocol according to the academic year.

\begin{tabular}{|c|c|c|c|c|c|c|c|}
\hline \multirow[b]{2}{*}{ Variable } & \multicolumn{2}{|l|}{ Academic year } & \multirow{2}{*}{\multicolumn{2}{|c|}{$\mathbf{p}$}} & \multirow[b]{2}{*}{ OR } & \multirow[b]{2}{*}{ IC $95 \%$} & \multirow[b]{2}{*}{$\operatorname{FER}(\%)$} \\
\hline & $\begin{array}{l}2014-2015 \\
n_{1}=41\end{array}$ & $\begin{array}{r}2015-2016 \\
n_{2}=68\end{array}$ & & & & & \\
\hline Study type & $28(68,3)$ & $53(77,9)$ & NSD & - & - & - & \\
\hline Study population / Target & $29(70,7)$ & $55(80,9)$ & NSD & - & - & - & \\
\hline Sample size & $9(22,0)$ & $6(8,8)$ & NSD & - & - & - & \\
\hline Variables studied & $32(78,0)$ & $55(80,9)$ & NSD & - & - & - & \\
\hline
\end{tabular}

This publication is licensed under Creative Commons Attribution CC BY 


\begin{tabular}{lllll} 
Judgment criteria & $22(53,7)$ & $48(70,6)$ & NSD - & - \\
Techniques used & $27(65,9)$ & $49(72,1)$ & NSD - & - \\
Statistical tests used & $6(14,6)$ & $19(27,9)$ & NSD - & - \\
\hline
\end{tabular}

NSD: Non-significant difference.

Table 3: Comparative study of the methodology and the study protocol according to the department.

\begin{tabular}{|c|c|c|c|c|c|c|c|}
\hline \multirow[b]{2}{*}{ Variable } & \multicolumn{3}{|c|}{ Departement } & \multirow[b]{2}{*}{$\mathbf{p}$} & \multirow[b]{2}{*}{ OR } & \multirow[b]{2}{*}{ IC $95 \%$} & \multirow[b]{2}{*}{$\begin{array}{l}\text { FER } \\
(\%)\end{array}$} \\
\hline & $\begin{array}{l}\text { Dentistry } \\
=33\end{array}$ & $\mathbf{n}_{1}$ & $\begin{array}{l}\text { Pharmacy } \\
n_{2}=76\end{array}$ & & & & \\
\hline Study type & $14(42,4)$ & & $67(88,2)$ & $<1$ p. 1000 & 10,1 & $3,8-26,9$ & 90,1 \\
\hline Study population / Target & $15(45,5)$ & & $69(90,8)$ & $<1$ p. 1000 & 11,8 & $4,2-33,3$ & 91,5 \\
\hline Sample size & $0 \quad(0,0)$ & & $15(19,7)$ & - & - & - & - \\
\hline Variables studied & $17(51,5)$ & & $70(92,1)$ & $<1$ p. 1000 & 11,0 & $3,7-32,2$ & 90,1 \\
\hline Judgment criteria & $8(24,2)$ & & $62(81,6)$ & $<1$ p. 1000 & 13,8 & $5,1-37,0$ & 92,7 \\
\hline Techniques used & $13(39,4)$ & & $63(82,9)$ & $<1$ p. 1000 & 7,5 & $3,0-18,7$ & 86,6 \\
\hline Statistical tests used & $0(0,0)$ & & $25(32,9)$ & - & - & - & - \\
\hline
\end{tabular}

\section{DISCUSSION:}

The comparability of our results remains limited due to the scarcity of work on the quality of medical writing. In addition to those having dealt with the difficulties of carrying out doctoral theses and dissertations [16-18], in particular the lack of training in research methodology [4]; most of the work has been devoted to their impact on scientific publication [19,20-29]. Applying only to so-called "original" articles [30], the variables in the section dealing with the methodology and the study protocol can only be studied on research dissertations as well as clinical cases which must also obey with the stereotyped structure, (IMRAD or similar structure) $[6,31,32]$.

For this section, the results also showed significantly higher frequencies at the level of the pharmacy department and no significant difference by academic year. The two least frequently cited items were sample size first, because not all research dissertations were necessarily based on sample surveys [109,110]; and secondly, statistical techniques, the value of which is often overlooked, if not unrecognized.

As for the proportions observed for the other parameters, they can be explained by the diversity of the types of studies that were the subject of research dissertations, particularly the clinical case, which was the subject of the vast majority of dental medicine dissertations. Nevertheless, and because of this, it was difficult to make a precise assessment of the methodological aspect by dispersing the criteria relating to each type of study. The difference between the two departments with regard to the category of dissertations also means that most of the parameters studied in terms of methodology and study protocol do not necessarily relate to the clinical case.

Despite a relatively satisfactory level of the editorial aspect of the methodology of the dissertations studied, the integration of training programs in the subject in the two cycles, graduate and post-graduate, is a necessity. It would be a lifelong learning tool for students; and a means of development for professionals and teachers. It would certainly contribute to improving the quality of scientific texts, dissertations, doctoral theses, communications and publications, and therefore to the promotion of scientific production.

\section{REFERENCES}

[1] 1. Maisonneuve H. Practical guide for the doctoral student. 7th edition. Paris: Scientific Editions L \& C, 2012: 81 pages.

[2] 2. Frangiere JP. How to pass a thesis? Paris: Dunod, 2016: 1-9.

[3] 3. Manzotti E, Allet N, Sabbatini M. How to write a thesis in university continuing education? Geneva: continuing education service. University of Geneva, 2010: 40 pages.

[4] 4. Teisset Y. Perception of thesis work by interns in general medicine at the Faculty of Tours. Doctoral thesis in medicine - state diploma. Tours: Academy of Orleans -Tours. François-Rabelais University. Faculty of Medicine of Tours, 2011: 103 pages.

[5] 5. Canadian Dermatology Association. How to review a manuscript [editorial] 2013;17(4):219-220. Journal of Cutaneous medicine and Surgery

[6] 6. Maisonneuve H, Lorette G, Maruani A, Huguier M. Medical writing. 5th edition. Paris: Doin, 2010: 211 pages.

[7] 7. Ministry of Higher Education and Scientific Research. People's Democratic Republic of Algeria. Order No. 731 of November 10, 2011, fixing the program for the 6th "transitional" year with a view to obtaining the degree of Doctor of Pharmacy. Official Bulletin of the Ministry of Higher Education and Scientific Research, 4th quarter 2001: 115-6.

[8] 8. Ministry of Higher Education and Scientific Research. People's Democratic Republic of Algeria. Order No. 733 of November 10, 2011, fixing the program for the 6th year "transitional" internship with a view to obtaining a doctorate in dental medicine. Official Bulletin of the Ministry of Higher Education and Scientific Research, 4th quarter 2001: 118-9.

[9] 9. Bouyer J, Hémon D, Cordier S, Derriennic F, Stüker I, Stengel B \& al. Epidemiology. Principles and quantitative methods. Paris: INSERM editions, 1994: 487 pages.

[10] 10. Bezzaoucha A. Epidemiology and biostatistics for the use of medical science students. Algiers: University Publications Office, 1996: 15-44.

[11] 11. Bezzaoucha A \& Dekkar N. Descriptive statistics and survey for health personnel. Algiers: National Institute of Public Health. 1988: 28-94.

[12] 12. Carrat F, Mallet A, Morice V. Biostatistics PACES - UE4 2013 - 2014. Pierre and Marie Curie University. Medical School. Update: October 2013. www.chups.jussie.fr (accessed January 11, 2017).

[13] 13. Bezzaoucha A. Statistical tests in medical sciences. Algiers: University Publications Office, 2004: 171 pages.

[14] 14. Schwartz D. Statistical Methods for Use by Physicians and Biologists. 3rd edition. Paris: Médecine sciences Flammarion, 1993: 31-239. 
[15] 15. Mesli MF and Bouziani M. Clinical epidemiology. Methodology guide. Oran: T com Gamma communication, 2010: 131-65.

[16] 16. Harriague JB. Difficulties encountered by general practitioners in supervising a general medicine thesis in Aquitaine. Thesis for obtaining the state diploma of Doctor of Medicine. Bordeaux: University Bordeaux 2 Victor Segalen. Faculty of Medical Sciences, 2010: 100 pages.

[17] 17. Salmeh F, Yaghobian M, Shafipour V. Assessing medical interns' attitude to general practitioner thesis \& its performance challenges in Mazandran University of Medical Sciences. Journal of Nursing and Midwifery Sciences 2014:1(2):51-57

[18] 18. Tiercelin A. Study of the experience of thesis work by the interns of General Medicine at the faculty of Caen. Thesis for obtaining the degree of Doctor of Medicine. Caen: University of Caen. Faculty of Medicine, 2012: 175 pages.

[19] 19. Togbey KMT. Panorama and become a scientist of a decade of medical and pharmacy theses relating to child health in Mali. Thesis for obtaining the degree of Doctor of Medicine (state diploma). Bamako: University of Bamako. Faculty of Medicine, Pharmacy and Odontostomatology, 2009: 84 pages.

[20] 20. Nougairede P. Etude PubliThèse: Exploitation rate of theses in general medicine within the Denis Diderot Paris 7 faculty. Thesis for the doctorate in medicine (state diploma). Paris: Paris Diderot University - Paris 7. Faculty of Medicine, 2009: 79 pages.

[21] 21. Baufreton C, Chrétien JM, Moreau-Cordier F, Moreau F, Portefaix H, Branchereau $\mathrm{H} \&$ al. Scientific output resulting from initial training at the Angers medical school between 2002 and 2008: of good quality but insufficient. The medical press 2012; 41 (85): 213-4.

[22] 22. Salmi LR, Gana S, Mouillet E. Publication pattern of medical theses, France, 1993-98. Medical education 2001;35:18-21.

[23] 23. Frkovic V, Skender T, Dojcinovic B, Bilic-Zulle L. Publishing Scientific Papers Based on Master's and Ph.D. Theses from a Small Scientific Community: Case Study of Croatian Medical Schools. Croatian Medical Journal 2003;44(1):107-11.

[24] 24. Nieminen P, Sipila K, Takkinen HM, Renko M, Risteli L. Medical theses as part of the scientific training in basic medical and dental education: experiences from Finland. BMC Medical Education 2007, doi:10.1186/1472-6920-7-51. www.Biomedcentral.com.
[25] 25. Debbiche AC, Mrabet A, Abidi E, Falfoul Borsali N, Dziri C. Impact of pathology theses defended at the Faculty of Medicine of Tunis (2000-2010). Medical Tunisia 2016; 94 (3): 172-5.

[26] 26. Pitche PT, Onipoh D, Tchangai-Walla KL. Become a scientist for the doctoral degree in medicine theses defended at the University of Lomé (Togo). Medical Education 2007; 8 (1): 24-9.

[27] 27. Pitche PT, Onipoh DK, Tchangai-Walla KL. Becoming a scientist in medical theses supported at the University of Lomé (Togo). Health Notebooks 2007; 17 (2): 117-20.

[28] 28. Gaundong Mbéthé GL, Grenouillet-Delacre M, Salmi LR, Mercié P, Longy-Boursier M. Future of works published in the form of summaries in the proceedings of the biannual congresses of the French National Society of Internal Medicine. The Journal of Internal Medicine 2008; 29 (12) 1080-82.

[29] 29. Rabenda V, Buckinx F, Bruyère O, Quabron A, Cooper C, Reginster JY $\&$ al. Publication outcomes of the abstracts presented at the 2011 European Congress on Osteoporosis, Osteoarthritis and Musculo-Skeletal Diseases (ECCEO-IOF11). Arch Osteoporos (2015). DOI 10.1007/s11657-015-02165.www.2016.wco-iof-esceo.org.

[30] 30. Soyer P, Taourel P, Trillaud H, Vicaut E, Laurent F, Dion E. Why and how to write and publish an article for a radiological journal. Journal of Radiology 2011; 92: 171-82.

[31] 31. Lorette G, Genier B. What kind of article is this? Ann Dermato Venereol 2003; 130: 1084.

[32] 32. Cohen H. How to write a patient case report. Am J Health-Syst Pharm 2006;63:1888-92.

\section{AUTHORS}

First Author - Djamila ADJIRI, Professor of physiologie Physiology laboratory. Faculty of Medicine - Ferhat ABBAS University - Sétif 1 - ALGERIA., Tel/fax : 21336667622 Mobile : 2136615818 22, Email : adjiridjamila@univ-setif.dz , adjiridjamila@gmail.com 